\title{
Introductory Service-Learning Experience: Macau College Students in Ethnic Minority School of Mountain Area in China
}

\author{
Lu Ching Hui, Chen Zi Yan, Yang Zi Yi
}

\begin{abstract}
This paper described how university students from Macau took social responsibility in China through Service-Learning project. It was an introductory experience for the student participants and for the children in the mountain area as well. This study aimed at raising children's interest in learning and their desire of continuing study. Results were reported in four themes: (1) increasing personal competence of teamwork spirits, leadership and service skills; (2) students' perception towards poverty issue and education in China rural and mountain areas; (3) having commitment to the next service; (4) realizing that ServiceLearning must be a mutual process. This paper also provides an overview of how a livinglearning community dedicated itself to community service to educate residents holistically.
\end{abstract}

Keywords: service-learning, poor alleviation, education, residential college

\section{Introduction}

In 2018, the Macau Special Administrative Region (SAR) Government was committed to following the Central Government's policy of precision poverty alleviation in Congjiang, Guizhou Province (Coutinho, 2018). In July 2018, Cheng Yu Tung College of University of Macau (CUM), as a living-learning community and a leading university in Macau, conducted an investigation to understand their needs. After meeting with local government officials and school principals, the College launched its very first Service-Learning program in December 2018, to provide volunteers to teach Mandarin, music, physical education and arts courses at one targeted school.

"D" Primary School was located in the mountainous area and people were from a Chinese ethnic minority-Miao. Most villagers were illiterate and few spoke the Mandarin language at work or at home. Since China's reform and liberalization, only two residents had earned high school diplomas in a village of two thousand people. In the face of scarce educational resources, "D" Primary School's learning environment offered only kindergarten, first grade, and second grade. Children were reluctant to attend third grade schooling in other villages due to low learning motivation, transportation difficulties, or their parents' orders. This project aimed at raising interest in learning for sixty-seven second-grade children, and motivating them to further their education. At the same time, it was a first-time service experience for most of the Macau students. In the end, it showed that thirteen students from the College students developed a greater social responsibility to motherland China, in response to Macau SAR government policy. 


\section{Literature Review}

Macau SAR's Policy of Poverty Alleviation in Guizhou

On May 23, 2018, Chui Sai On, Chief Executive of the Macau Special Administrative Region (SAR) Government, and Zheng Xiaosong, Director of the Liaison Office of the Central People's Government in the Macau SAR, led a delegation to Guizhou Province. Together, they signed a "Poverty Alleviation Cooperation Framework Agreement" with Guizhou's Provincial Government to launch a jointly administered poverty alleviation program. Macau SAR agreed to further cooperation between Guizhou and Macau in five areas: (a) tourism; (b) commerce; (c) education; (d) agriculture; and (e) informatization (i.e., make the local economy and society more information-based).

Furthermore, Macau SAR Government would provide focused assistance to Congjiang County through "precise poverty alleviation work", in eight areas: "industry, tourism, culture affairs, education, healthcare, talent development, employment transfer, and donation" (Zhao, 2018). Moreover, the Chief Executive stressed the SAR Government would strive to encourage further participation from the Macau community to reduce poverty in Guizhou. In addition, according to the agreement, the Macau SAR Government allocated funds not exceeding 30 million renminbi to support rebuilding a primary school campus in Congjiang County. This " $D$ " Primary School is the target of this study.

\section{Miao People and "D” Village Community}

"D” village's population was mainly composed of one Chinese ethnic minority, the Miao. The village was located on a high slope, transportation access was difficult, and communication was not easy. Most of the villagers spoke Miao instead of Mandarin. The Miao people are the fifth largest ethnic minority in Mainland China (Han are the majority). Miao people had their own religions and complex customs. In order to protect Miao's bloodline, Miao have strong traditions that prompt them to stay in close-knit, communities, regardless of living in harsh conditions for thousands of years in rural and mountainous areas (Yang \& Zhao, 2013).

The "D" villagers still lived a very traditional farming life. " $D$ " village had a total of two thousand people, and as of 2018, three hundred and forty-six people still lived in households defined as poverty-stricken. "D" Primary School was located in the center of "D" Village, twenty-six kilometers away from the closest city. It had two hundred and sixteen students in one kindergarten, three first-grade classes, and two classes of second-graders. Nine teachers worked there, and only one possessed an undergraduate degree. Due to its mountainous location, "D" Primary School and its village regularly face a water shortage for two to three months out of every year, and they struggled to provide clean drinking water. 
University of Macau implemented its Residential College system after relocating to its new campus in 2014. As of today, it has established ten living-learning residential colleges. The objective of the University of Macau's whole-person education model was to nurture selfreflective, caring, and socially responsible individuals who can grow in a challenging and multicultural environment (Chen H. D \& Gong H, 2016). To achieve this objective, Cheng Yu Tung College organized several programs with the goals to encourage students to practice what they learn in class and contribute to the community, and transforming them into global citizens with sense of responsibility and patriotism.

\section{Service Learning and Citizenship}

The College designed the project based on a modified version of Fertman, White and White's model (1996). The model comprised four phases, entitled preparation, service, reflection and celebration. In the preparation phase, the team had to understand "D" Primary School and its students' backgrounds, obtain the school's support and establish Service-Learning goals, providing College volunteers with teacher training. In the service phase, the team moved from exploration to understanding and from a group mode to a mindset of caring for each individual student. In the reflection phase, the team performed group and individual reflection, from What (what I did), So What (what I learned), Now What (what I do with what I learned). In the celebration phase, the team demonstrated the teaching outcomes to parents, the community and the college (Jacoby, B., 1996).

The model's authors believed that students acquire knowledge more quickly when solving practical problems, while service learning provides such an environment. College students strove to communicate with Miao children who did not speak Mandarin fluently. The children's behavior and the College students' reflection amply demonstrated service learning's theoretical claim of "service, combined with learning, adding value to each and transforming both" (Eyler, J\& Giles, D.E, 1999). Furthermore, service learning provided an ideal environment for bringing together disparate qualities of values, knowledge, skills, efficacy and commitment into effective citizenship development. Students first feel a sense of social responsibility and then acknowledge the importance of social justice. Students find the motivation to do more, by looking at their results and seeking ways to improve them. In trying to make a more effective difference, they may revise their strategies or even take some risks, by which they gain experience and self-confidence. Service learning has the capacity to develop students who felt connected to community to commit themselves to engaging in the next service. To sum up, participation in service learning led to the values, knowledge, skills, efficacy, and commitment that underlay effective citizenship (Eyler, J \& Giles, D.E 1999).

\section{Service Leaning in China}

Since the implementation of reform and opening-up, China has witnessed many groundbreaking changes within its culture, economy, and education. The country makes rapid 
gains in digitalization, globalization, and economic development. In today's ever-changing society, new opportunities and challenges constantly emerge. As a result, people struggled with the difficulty of meeting the high demands of this rapidly evolving environment. (Ma, Chan, Liu \& Fong, 2018). By a continuous improvement in education levels, more and more institutions, including high schools and universities in China, began to nurture students with multiple skills, abilities and sense of social responsibility to adapt to this changing world. For instance, in 2001, China promoted the Volunteer Service Act, classifying voluntary service as a means for fulfilling civic duty.

Chinese government and institutions acknowledged that education should go beyond to classroom instruction. More importantly, students ought to join society and apply what they have learned to practice and contribute to society. After all, theory and application were complementary and mutually enforcing. However, compared to other regions or countries in Asia such as Hong Kong, Taiwan, Singapore, Philippines, etc., service-learning projects for credit or in a formal class setting were still not common in Chinese higher education. (Guan \& Xiong, 2011).

\section{Project Design and Student Participants}

The College designed this service-learning experience with residential college students in mind. Out of thirteen participants, five were male and eight were female. Most were from academic disciplines other than teaching primary school. Only one student had prior experience doing volunteer service while at university. It was a non-credit, living-learning project taught by a College Resident Fellow, faculty members, non-government organization personnel, as well as university students from Congjiang, Guizhou. The project included sixteen hours of classroom instruction and preparation, twenty-four hours of community service, and six hours devoted to evaluation.

\section{Teaching Approach}

In the service process, a "communicative approach" informed a small group discussion. This study divided sixty-seven students into twelve groups and a teaching assistant took charge of each group. While one student instructor was in the front teaching, other teaching assistants made sure the children knew what to do and responded correctly. The teaching method trained children's ability in three aspects: linguistic competence (its grammar and vocabulary), sociolinguistic competence (how to use and respond to language appropriately) and strategic competence (recognize and repair communication breakdowns before, during, or after they occur) (Richards \& Rodgers, 2001). Additionally, students learned a variety of teaching aids and many interesting activities as another teaching approach. The teaching aids were diverse to arouse different children's attention and interest. For example, children would play clarinet, use the labyrinth to practice mandarin, or have time for creative painting. With the mentoring and supervision of teaching assistants and student instructors, children had the opportunity to receive responsive care and attention. The project was student-centered, especially for those children who were shy or unable to use Mandarin to express themselves. 
Study Evaluation

This study used a qualitative description method to collect and analyze data. The authors collected data by several means, including verbal presentation of student reflections in personal meetings, students' written journal reflections, instructor's observations, and the partner institution's feedback. In their analysis of teaching results, the authors interviewed the school principal and some Primary School student representatives to evaluate this project.

Journal reflection covered topics such as the meaning of service learning, poverty alleviation, policy-making, the educational system, a sense of social responsibility and personal growth such as teamwork spirits, cultural engagement, and service and leadership skills. The authors coded all this data to develop a number of meaningful conceptual units. Two researchers codified separately, and subsequently compared each other's categorizations.

\section{Results and Discussion}

Four major themes were identified as students undertook the project: (a) increasing personal competence of teamwork spirits, leadership and service skills; (b) college students' perception towards poverty issue and education in China rural and mountain areas; (c) fostering the sense of commitment and social responsibility; and (d) it was a mutually beneficial learning process.

Increased Team Spirit, Personal Competence, Leadership, and Service Skills

The training helped the volunteers understand the Miao's ethnic minority culture, find the meaning of service learning, and discover how to communicate with one another. This introductory service experience improved their team spirit and ability in all phases. Volunteers also gained a greater appreciation of leadership and service:

This Service-Learning journey was my happiest journey, and my working group was very united and attentive. From the preparation to the on-site teaching, everyone contributed his or her time and ideas selflessly. If we had any disagreement, we would listen, discuss and analyze it carefully in order to develop a more appropriate teaching plan for the children. (\#4)

We had to teach in front of the classroom. We needed to instruct our teammates and the kids. Then we would become teaching assistants in turn. This made each of us a leader and a good follower. (\#5)

I am grateful that we had each other. We learned how to lead out of love and service. " (\#10) 
At the beginning, I thought being the instructor in the front of the classroom would be the most exhausting job, but after the first day, I found that being the teaching assistant with children was the hardest. After that, I realized the importance of teamwork: we had to work closely. It was necessary to communicate with each child, making sure they understand what the instructor meant. I also had to learn to how to manage time and allocate some tasks for the children in order to achieve the purpose of each lesson." (\#12)

College Students' Perception towards Poverty Issue and Education in China Rural and Mountain Areas

College students saw firsthand the link between poverty and poor quality education. As mentioned above, out of nine teachers in "D" Primary School, only one had a bachelor's degree. Compared with advanced countries in Asia or elsewhere, the standard for teachers here is still low (National Institute of Education Science, 2010) and it influences the teachers' attitude to their children's education. A lax attitude made teaching harder and it is quite difficult for college students to communicate with the school equally. Poverty alleviation must have both economic and humanitarian aspects.

Everyone has the right to get an education. Equipping our mind and brain makes us stronger and that is when we will not need poverty alleviation support. We walk ourselves out of poverty! (\#2).

It is a very good to see that Macau SAR Government tried to support educational affairs. I think that cultivating the young generation will help the most in the long run. It is also crucial for the local teachers to learn more and do more for their own students (\#4).

I think the kids should get more education, not only to get rid of poverty but also be more rigorously prepared to protect their own precious culture!” (\#9).

I think another way to alleviate poverty is to set up a team of teachers to train the teachers in this rural and mountain area of China. Only when the teachers improve can our children be educated out of poverty faster. (\#3)

Fostering a Sense of Commitment and Social Responsibility

Children's ability of speaking Mandarin and desire of learning was better than expected. By taking care of every student in small groups, they were willing to communicate in Mandarin. The "D" school did not provide formal classes in arts, physical education and music until the College team came. Children proudly and happily asked their parents to join the celebration party. The principal highly praised the team's contribution and hoped they would come again. 
Furthermore, in last July's investigation, the school paid more attention to teaching subjects, but overlooked the personal hygiene or moral education of the village children. The project found that children in mountainous areas had serious illnesses in winter, made worse by the persistent water shortage. Moreover, children did not maintain an orderly classroom. They pushed each other and walked around during the meal. Plainly, their etiquette needed to improve. Above all, the team members felt fulfilled but encountered new tasks and challenges, leaving them feeling obligated to do more. It was encouraging to see nine out of the thirteen participants commit to do the service again.

You found you had some impact on other people, the kids, the teammates... from their reaction you started to think more about yourself. This was a powerful and meaningful experience" (\#11)

I spent lots of time wondering if it was meaningful to do this service. Then I realized children might not grow that fast, they might not learn that much from me. However, I am sure they were happy and felt the warmth of the larger society. They are loved. If we have more people get involved, it will be a big success! (\#8)

Service learning may be more difficult than expected, but if we chose to join, we should do it with heart for that we may affect other person's life forever. No matter how difficult the road is, we must be unremitting." (\#3)

Service Learning Was a Mutually Beneficial Learning Process

College students and "D" Primary School realized that service learning was a two-way, reciprocal process. Unlike traditional volunteer projects or charity actions, service-learning programs contained designed learning plans, thorough preparation, structured reflection and concluding celebration. While providing services to the outside world, College students learned from the children. The meeting of different life experiences made students understand the importance of understanding and respect more clearly.

In the teaching process, the team found out some parts of "Curriculum Guidelines for Primary Schools in Mainland China", the basic skills that students should master in each grade, were missing in "D" Primary School. For example, art class required the mastery of creating and handcrafting. Local teachers in "D" Primary School were not qualified art teachers and with the lack of teaching materials and resources, they did not know how to conduct art classes in a scientific and systematic way. Therefore, the team taught from the RGB color model and then moved to teach how to make paint the Beijing opera facial masks and do the hand- made windmills. Teachers in the "D" Primary School had the chance to learn and continued to use the teaching materials after the team left and as well as the PE courses and Music courses.

Studying together was a wonderful moment. I like their childlike innocence, which was the beautiful nature of children and what I had been looking for a long time." (\#7) 
When we were coaching children one by one, I realized that everyone, no matter at what age or in what kind of environment they grew up, they wanted strongly to be taken seriously. I have learned to understand others better and to consider from their perspectives which also increased my empathy during my very first time ServiceLearning experience.” (\#8)

I quite agreed with the sentence, 'during the service, what we learn might be always greater than what we served'. We went into minority villages, experiencing different life styles and learned different cultures. I have learned a lot and I did hope the children too." (\#6)

\section{Conclusion}

This study provided an overview of how university students from Macau took social responsibility in ethnic minority school of mountain area in China through Service-Learning project. The main purpose of this Service-Learning project was to enhance children's interest in learning so they were willing to continue to study. The project achieved these goals. Children showed interest in learning and they actively participated in class activities. Children asked their parents to school to witness their learning outcomes, and reinforced their willingness to pursue more education. Macau College students showed improved team spirit, leadership and service skills. They felt connected to the community and two-thirds of them made a commitment to doing the service again next year. The institution acknowledged their students' effort and enthusiasm. Though it was a first-time service-learning experience for both the College students and the school, it showed that both communities benefited and learned a lot.

Nevertheless, the study had its own limitations. The project took place during the Christmas holidays. The team only had three days to do its teaching. It was not easy to provide a more complete and thorough learning experience for children even though the communicative teaching approach worked excellently. On the other hand, while the team focused on the children's immediate learning interests, better training for local teachers in " $D$ " school is of crucial importance as well. This service-learning project will take place again. In the second project, planners should extend greater consideration to training for the teaching staff, and the children's personal hygiene and manners. 


\section{References}

Chen H. D \& Gong H (2016) Studies on the education of residential colleges in today's universities. Xi'an, China: Xi' an Jiaotong University Press.

Eyler, J\& Giles,D.E (1999). Where's the learning in service learning? San Francisco, CA: Jossey-Bass.

Hok-ka, C., Mui-fong, F., \& Cheng, A. (2018). Service learning and the aims of Chinese higher education. In Hok-ka C., Mui-fong F., Cheng A., \& Cheung-ming A. (Eds.), ServiceLearning as a New Paradigm in Higher Education of China (pp. 17-44). East Lansing: Michigan State University Press. Retrieved from http://www.jstor.org/stable/10.14321/j.ctt2111gc9.5

Jacoby, B. (1996). Service learning in today's higher education. San Francisco, CA: JosseyBass.

Coutinho, P. (2018 May 25). Macau sign agreements aimed at poverty relief in Guizhou, Macau Daily Times. Retrieved from https://macaudailytimes.com.mo/macau-signsagreements-aimed-at-poverty-relief-in-guizhou.html

Richards, J. C., \& Rodgers, T. S. (2001). Approaches and methods in language teaching. (2nd Ed.). Cambridge: Cambridge University Press.

Wang, J. (1990). Compulsory nine-year education in China: Issues and prospects. Journal of Education Finance, 15(4), 487-497. Retrieved from http://www.jstor.org/stable/40703838

Zhao, F.Y(2018.5.23).Macau offers poverty-relief help to Guizhou,Xinhuanet. Retrieved from http://www.xinhuanet.com/gangao/2018-05/23/c_129878753.htm

關爾佳、熊紫珺(2011)論中國高校“服務學習”的 現狀及發展前景。中國青年研究, 8 , 100-103。取自 Retrieved from

http://xueshu.baidu.com/usercenter/paper/show?paperid=9baa45ea1c34ed82b7a0fa $788783 \mathrm{bb}$ d1\&site=xueshu_se

楊成光、趙斌(2013)。貴州苗族原始宗教文化研究。中國經濟研究導刊，4，268-269。 取自 https://wenku.baidu.com/view/804b0dde26fff705cc170a7d.html?from=search 


\section{Author Information}

Ching Hui, Lu

Resident Fellow

G039 W23

Cheng Yu Tung College

University of Macau

Macau, China

dianelu@um.edu.mo

Ms. Lu received her master degree on Student Affairs of Higher Education in National Taiwan Normal University. She has worked as a resident fellow in University of Macau for more than 5 years. Ms. Lu conducts many leadership and service programs and the Guizhou service-learning project was one of them. Before joining UM, she had worked in National Taiwan University for 7 years.

Zi Yan, Chen

Sophomore in English Education

G039, W23 Cheng Yu Tung College

University of Macau

Macau, China

czy201225@gmail.com

Ms. Chen is a year-two undergraduate from University of Macau and majors in English education. She wants to become a teacher to help students get a better future. This was her first time doing Service-Learning program as a university student. She was in charge of arts courses on site, and enjoyed the process of teaching and playing with the children.

Zi Yi, Yang

Freshman in Business Administration

Cheng Yung College/Macau, China

G039, W23 Cheng Yu Tung College, University of Macau

Macau, China

dianelu@um.edu.mo

czy201225@gmail.com

yangziyi2345@126.com

Ms.Yang is a year-one undergraduate from University of Macau and majors in business administration. She did volunteer service when she was in high school in mainland China. This was her first service-learning program as a university student. She was in charge in Mandarin courses when she was in the service site. 